days to come, every boy (and girl) on leaving school will have reliable information as to the kind of work in which he can most effectively use the ability he possesses, with pleasure and satisfaction to himself and to his employer. In this case the hopeless situation involved in "the square peg in the round hole' will tend to disappear.

In dealing with modern movements in education it is necessary to make a passing reference to the great possibilities offered by the cinema and the wireless. Experiments in various directions have been, and are still being, made to explore methods which may result in one, or, still better, both, playing a useful part in modern schemes of education. The natural objections raised to purely visual or purely auditory instruments in educational procedure may be met within the near future by the speaking film or the synchronisation of the normal educational film with the loud-speaker, thus eliminating the obvious necessity of the film lecturer.

The comparative failure of the so-called educational film in picture houses is largely due to the attempt to satisfy the student, and at the same time to secure the interest of the larger clientèle of the picture palace, the popular audience, which is rendered necessary for financial reasons. During the sitting of the Cinema Commission, an investigation was made of the popularity of different types of film among the school children frequenting picture palaces. In practically every case the educational film was at the bottom of the list. It did not appear possible to meet the claims of the two classes of patrons, although praiseworthy attempts were made to produce exceptionally good results from the point of view of successful production. For educational purposes it is evident that the element of popular appeal must be subordinate to the instructional objective.

On the other hand, a valuable research has been carried out, aided by generous subventions by the Carnegie Trust and the National Council of Public Morals, to test the efficacy of the moving picture (film) as compared with the static picture (lantern slide) for teaching purposes. Prof. Spearman accepted the chairmanship of the committee appointed, and his psychological laboratory at University College, London, was fitted up with cinema appliances for the conduct of the investigation. Groups of children from neighbouring schools were instructed in different subjects by means of the lantern and the film respectively. The result was that there appeared to be an advantage of about 20 per cent for the moving picture both for immediate and delayed memory tests.

Many schools have recently experimented in using broadcast material as part of the general scheme of instruction with considerable success, any initial difficulties having been successfully overcome. It is probable that, in the days to come, the employment of the means of instruction offered by the cinema and broadcasting, either separately or together, will exercise increasingly useful functions in educational processes.

\title{
The Gorgas Memorial Laboratory of Tropical Disease.
}

$\mathrm{I}^{\mathrm{N}}$ $\mathrm{N}$ fitting tribute to the memory of General Gorgas, 'The Redeemer of the Tropics', the Congress of the United States of America, at its session which closed on May 29 last year, authorised a permanent annual appropriation out of the United States Treasury of 50,000 dollars, as the contribution of the United States towards the maintenance and operation of the Gorgas Memorial Laboratory on the Isthmus of Panama.

On July 4, 1920, there died an American citizen, William Crawford Gorgas, who, from an obscure doctor in the United States Army Medical Corps, rose to become the greatest tropical sanitarian of history. He served as chief sanitary officer of Cuba from 1898 until 1902 ; as chief sanitary officer of the Panama Canal Zone from 1904 until 1907 ; as member of the Isthmian Canal Commission from 1907 until 1914, when the Canal was completed, and as Surgeon-General of the United States Army in the World War, from 1914 to his retirement, at sixty-four years of age, on Oct. 3, 1918. To him was given the vision and practical ability to make possible the conquest of disease in the tropics. He eliminated yellow fever from Havana, pursuing his plans in the face of great opposition, ridicule, and indifference. His successful campaigns in both Cuba and Panama for the suppression of mosquitoes greatly reduced the ravages of yellow fever and malaria, and made possible the conversion of a pestilential region into a safe cross-roads for the ships of the world.

The Gorgas Memorial Institute of Tropical and Preventive Medicine (Inc.) was created after the death of Gorgas, by his assistants and co-workers in the War, eminent physicians, surgeons, and sanitarians of international reputation. It forms no inanimate monument, but a living, working memorial to perpetuate the man's name by carrying on his ideas and ideals.

The key-note of the 'Gorgas idea' is that health is the foundation of our social and economic structure. The fundamental purpose of the Gorgas Memorial Institute is to conduct research into all preventable diseases, and to train men and women to assist in this prevention. Two main lines of approach are contemplated for the accomplishment of this purpose :

(a) A national educational campaign, through such channels as public press, radio and cinema, featuring the contributions of medicine to human progress, and the share and responsibility of the public in these contributions.

(b) The intensive study, in the tropics, of the causes and prevention of disease.

The first half of this programme has already been well organised and shown splendid results. The second half is now made possible under the terms of the Act and by means of funds thereby 
authorised, and with the co-operation and aid of the Latin-American countries invited and authorised by the Act. The work of the Gorgas Memorial Institute has thus far been maintained wholly by funds raised through popular contributions.

Even with the assured prospect of funds, however, the purposes of the Institute remain purely humanitarian and scientific. It operates without profit; no part of the endowment fund is to be spent for buildings or equipment, nor any investment to be made in elaborate offices. The Republic of Panama has given a site and guaranteed initial buildings and equipment for tropical research laboratories, in recognition of Gorgas's great work in Panama, and is conducting a campaign to raise its quota for the endowment fund. Through economical administration the overhead expenses are kept extremely low. Those invited to serve as founder members are asked to subscribe 100 dollars to the endowment fund.

Governing boards are formed on the basis of 100 members to $1,000,000$ population. Seventy-five per cent of the personnel of each committee will consist of medical men, and twenty-five per cent of influential laymen and women. The permanent activities of the organisation will be supervised by these governing boards sitting in their respective States.

The need and value of the proposed tropical research work are enormous. We have only to remember the conquests of yellow fever, malaria, and bubonic plague to realise the incalculable results which may come from the discovery of the method of transmission of a disease. On the single finding, by the Walter Reed Board in Cuba, that the Stegomyia mosquito is the transmitting agency of yellow fever, were based the great results in quarantine and mosquito work achieved in Cuba and Panama by the late General Gorgas, and the banishment from both these regions of this malignant, age-old plague. So, too, bubonic plague was brought under preventive control through the discovery that it was transmitted by the rat flea.

The malignant tropical maladies calling for further intensive laboratory research and study as to cause, transmission, control and prevention, are many. They include, among the better-known forms, malaria, yellow fever, leprosy, bubonic plague, sleeping sickness, amœebic dysentery, hookworm disease, etc. These diseases, it is true, are indigenous to the tropics, yet some of the most fatal-as leprosy and bubonic plague-may thrive with equal virulence and destructive power in the temperate regions. The almost universal scourge of malaria provides an ever-present problem of world-wide application. Finally, the discovery of sources and transmitting agencies of infection and of methods of control and prevention does not end the task. There remains the vital necessity of increased efficiency of these controlling and preventive measures.

While such research is the primary purpose of such an establishment as the Gorgas Memorial
Laboratory, its nature and position give it another character, namely, that of an important centre to which will be invited students from all countries, so that it may receive the best of international thought and that its findings on the causes and prevention of tropical disease may be disseminated throughout the world. In view of the vastness of the field involved, it is obvious that there will be no overlapping of activities of any of the existing institutions by the establishment of the Gorgas Memorial Laboratory, since the work will be mutually supplemental.

Another useful purpose is served by the cooperation of the Latin-American countries, already referred to. To quote Dr. Franklin Martin (chairman of the Board of Directors of the Gorgas Memorial Institute), "Not only will the work serve a great humanitarian purpose in itself, along the lines of the conquest of the malignant maladies of the Tropics, but it offers an opportunity for an added bond of friendship between the United States and her sister nations on the Western Hemisphere". The United States are as much concerned by protective measures as the countries of central and southern America, since diseases indigenous to the tropics are easily transplanted into temperate zones owing to increased facilities in transport. In fact, all nations of the world are equally concerned, and all discoveries made in the Laboratory will manifestly be of world-wide benefit.

In his evidence before the House of Representatives, the Hon. Maurice H. Thatcher quoted from Dr. Wellcome's testimony as follows :

"In respect to Panama being the ideal location for the Gorgas Memorial Tropical Research Laboratory, I would say that Sir Patrick Manson . . . considered Panama to be one of the great tropical disease danger centres of the world. A number of years ago he pointed out that ships passing through the Panama Canal, and to and from the Isthmus and all parts of the world, would bring and carry all manner of diseases-bringing and leaving diseases while picking up and carrying others to various parts of the world. Sir Patrick regarded this as a very serious matter, and he expressed to me repeatedly his very strong views on this subject. I have heard him make similar statements at the London School of Tropical Medicine and elsewhere. Furthermore, I know that General Gorgas also held that same view."

The Isthmus of Panama is a peculiarly suitable site for the establishment of the Gorgas Memorial Laboratory for many reasons. Lying as it does in the heart of tropical America, it forms a convenient centre for the study of tropical disease. The Panama Canal, as one of the great focal points of international traffic, forms also a passage-way for the possible transmission of disease to and from every quarter, providing an admirable centre for preventive work. Finally, it is but fitting that the memorial honouring the name of the man who rid this region of pestilence and made the building of the Canal possible should stand here at the crossroads of the world as a beacon light of safety and health, throwing its rays into all lands burdened with disease.

No. 3127, Vor. 124] 